Special Issue of the 8th International Advances in Applied Physics and Materials Science Congress (APMAS 2018)

\title{
Solid Particle Erosive Wear Behaviour of Flame Sprayed Ceramic Coatings
}

\author{
E. AltunCU ${ }^{a, *}$ And K. GÜZEL ${ }^{b}$ \\ ${ }^{a}$ Sakarya Applied Sciences University, Tech. Fac., Metallurgy and Materials Eng. Dept., 54187 Turkey \\ ${ }^{b}$ Sakarya Applied Sciences University, Institute of Natural Science., Manufacturing Eng. Dept., 54187 Turkey \\ Variety thermal spray coatings are used to improve wear performance and life span of part in many industrial \\ applications. The solid particle erosive wear mechanisms of the lamellar structured thermal spraying coatings are \\ not still clearly understood. In this study, the wear behavior of different oxide based coatings produced using the \\ flexicord flame spray gun developed in recent years has been investigated on many aspects. The wear rates of flame \\ spray coatings in different composition (alumina, chromia, spinel, zirconate) and thicknesses were compared. In \\ order to determine the effect of heat treatment on the wear performance, heat treatment was performed at $700^{\circ} \mathrm{C}$ \\ for $60 \mathrm{~h}$ and the wear rate of the coatings were measured. As a result, coating quality, thickness and composition \\ have been found to play an important role in erosive wear behavior. It has been observed that the wear rates vary \\ depending on the different angle of impact. Discontinuities in the coating structure, splat thickness and porosity \\ seem to affect the wear resistance of the coating. As a result of the work, it is understood that oxide based flame \\ spray coatings increase the wear resistance of the metallic part. Among these coatings, the best wear performance \\ has been demonstrated by chromium oxide coatings.
}

DOI: 10.12693/APhysPolA.135.895

PACS/topics: thermal spray, coating, oxide ceramics, solid particle erosion

\section{Introduction}

Solid particle erosion is a major wear problem in terms of many metallic surfaces. Based on structural features and material mechanical properties, failure occurence may have different mechanisms: in the case of brittle solids, the direct cracking is dominant; in the case of ductile solids, the mechanism of deformation, microcutting and/or low-cyclic fatigue prevails [1,2]. Under these erosive wear conditions, thermal spray coatings are highly effective engineering solution. Thermal spray coatings are widely used to protect metallic surfaces against abrasive wear, corrosion and high temperature effects and to improve lifesapan of parts. Therefore, high investment and operating costs of plasma and high velocity oxygen fuel (HVOF) spray coating systems are limiting factor [3, 4]. Flexicord flame spraying is a newly developed high velocity flame spray method which is an alternative economical method among the high energy thermal spray processes (plasma and high velocity oxygen fuel (HVOF)). Depending on the design and operating conditions of the spray gun, it has a high speed spraying capability. Due to the lower heat load on the substrate surface during the spraying process, the internal stresses are low and the desired coating thicknesses can be obtained. Compressed fine powders in a polymeric sheath (flexicord) provide a homogeneous melt and higher spraying rate than the conventional powder flame spray. It is seen that this coating method provides important advantages in terms of economically, especially in the case of solid particle erosion problems encountered in mixers, pumps, and conveyor

*corresponding author; e-mail: altuncu@sakarya.edu.tr systems. There is limited scientific study on erosive wear behavior of oxide based flexicord spray coatings. Solid particle erosion is a dynamic process that leads to progressive loss of material from the target surface and coating due to impingement of fast moving solid particles [5]. In this study, different oxide based ceramic coatings have been subjected to solid particle erosive wear test according to ASTM G76 standard in heat treated and non heat treated conditions [6].

\section{Experimental procedure}

In experimental study, AISI 321 grade austenitic stainless steel plates $(50 \times 25 \times 4 \mathrm{~mm})$ are preferred as substrate. Plates were sand blasted with $\mathrm{Al}_{2} \mathrm{O}_{3}$ (60-80 mesh) at 3 bar pressure, $90^{\circ}$ angles at $200 \mathrm{~mm}$ distance to create roughness to ensure adhesion. The coating process was carried out in two stages: a $\mathrm{NiCr}-$ based bond layer with a thickness of 50-70 $\mu \mathrm{m}$ to ensure better adhesion of the ceramic layer, followed by spraying the oxide ceramic $\left(\mathrm{Al}_{2} \mathrm{O}_{3}, \mathrm{Zr}_{2} \mathrm{O}_{3}-\mathrm{MgO}-\mathrm{Al}_{2} \mathrm{O}_{3}, \mathrm{Al}_{2} \mathrm{O}_{3}-\right.$ $\mathrm{MgO}, \mathrm{Cr}_{2} \mathrm{O}_{3}$ ) coating layers with the appropriate spray parameters. The chemical composition and experimental coding of the powders used in experimental studies are presented in Table I. The main parameters in the coating process, gas mixture ratio, feed rate and spray distance control the quality of the coating. Table II presents the optimized thermal spray process parameters. There are certain discontinuities (microcracks, micro porosity) in the coating structure after thermal spray coating operation. These discontinuities can be reduced by heat treatment. The coated test specimens were heat treated at $700^{\circ} \mathrm{C}$ for $60 \mathrm{~h}$ in the atmospheric furnace. After being cooled in the furnace, it was subjected to erosive wear tests (ASTM G76 standard). In the wear test; at 400 
TABLE I

Chemical compositions of feedstock materials.

\begin{tabular}{l|l}
\hline \hline \multicolumn{1}{c|}{ Coating Layers - Codes } & \multicolumn{1}{|c}{ Composition [wt\%] } \\
\hline bond coat - BC & $\mathrm{NiCr} \mathrm{80,20}$ \\
magnesium zirconate - $\mathrm{ZM}$ & $\mathrm{Zr}_{2} \mathrm{O}_{3}-\mathrm{MgO}-\mathrm{Al}_{2} \mathrm{O}_{3} 75,21,4$ \\
spinell - $\mathrm{S}$ & $\mathrm{Al}_{2} \mathrm{O}_{3}-\mathrm{MgO} 70,30$ \\
alumina - A & $\mathrm{Al}_{2} \mathrm{O}_{3} 99.7$ \\
chromia - C & $\mathrm{Cr}_{2} \mathrm{O}_{3} 99.2$
\end{tabular}

TABLE II

Spray parameters of the coatings.

\begin{tabular}{c|c|c|c|c}
\hline \hline $\begin{array}{c}\text { Layer } \\
\text { codes }\end{array}$ & $\begin{array}{c}\mathrm{O}_{2} \\
{[\text { bar] }}\end{array}$ & $\begin{array}{c}\mathrm{C}_{2} \mathrm{H}_{2} \\
{[\mathrm{bar}]}\end{array}$ & $\begin{array}{c}\text { Air } \\
{[\text { bar] }}\end{array}$ & $\begin{array}{c}\text { Distance } \\
{[\mathrm{mm}]}\end{array}$ \\
\hline $\begin{array}{c}\text { bond coat } \\
\mathrm{ZM}\end{array}$ & & & 4.5 & $100-120$ \\
$\mathrm{~S}$ & 4 & 1.2 & 4 & 120 \\
$\mathrm{~A}$ & & & 4.5 & $110-120$ \\
$\mathrm{C}$ & & & 4 & $100-130$ \\
& & & & $80-100$
\end{tabular}

\section{Non-heat treated samples}

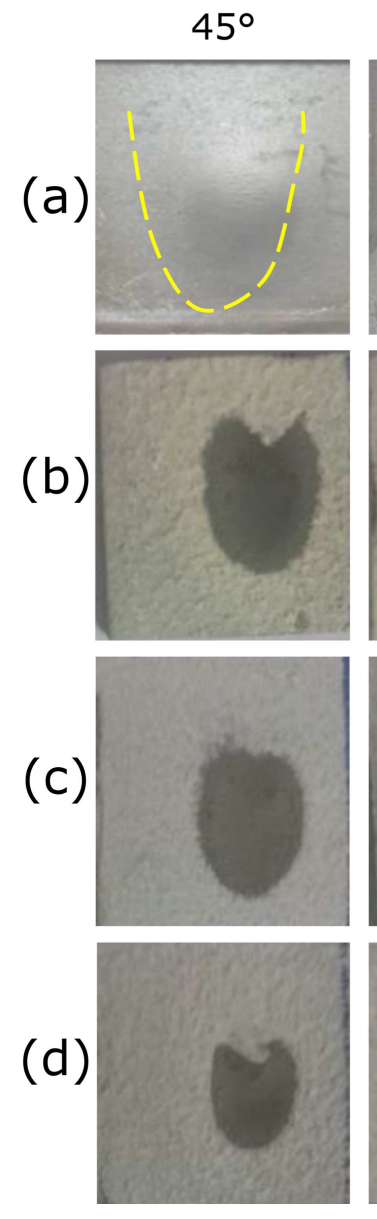

$90^{\circ}$
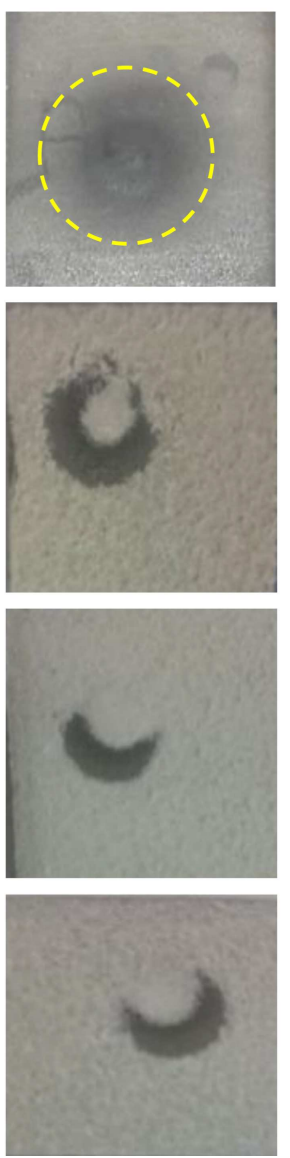

mesh size $(\approx 45 \mu \mathrm{m})$, sharp angled alumina $\left(\mathrm{Al}_{2} \mathrm{O}_{3}\right)$ particles are used and sprayed with static pressure of 1.5 bar for $10-45 \mathrm{~s}$ at different angles $\left(30-90^{\circ}\right)$ onto the surface. Erosion rate, defined as the coating mass loss per unit erodent mass $(\mathrm{mg} / \mathrm{kg})$ was calculated. The top surface morpholgy of the coated specimens before and after the erosive wear test were investigated by scanning electron microscopy. Surface roughness is measured by $3 \mathrm{D}$ profilometer. micro hardness $\left(\mathrm{HV}_{0,2}\right)$ measurement was performed in the coating section after standard metallographic preparation.

\section{Results and discussion}

All coatings with optimum process parameters have been successfully produced with the flexicord flame spray technique. Wear tests were applied at different solid particle impact angles on both heat treated and non-heat treated surfaces. Obtained test results are discussed and showed below. Wear tracks and regions on the coatings and substrate are shown comparatively in Fig. 1.

\section{Heat treated at $7000^{\circ} \mathrm{C} 60 \mathrm{~h}$ samples}
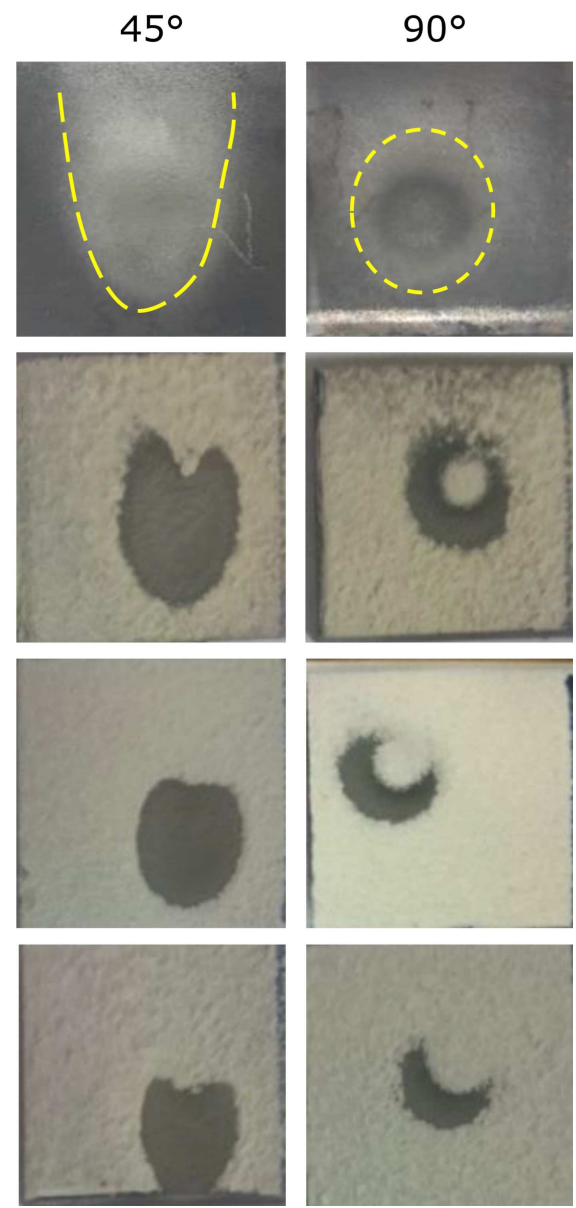

Fig. 1. Wear track profiles before and after heat treatment (a) substrate, (b) zirconate, (c) alumina, (d) spinel. 
It is observed that the solid particle abrasive particles change the form of wear trace on the surface depending on the angle of impact to the surface. When the erosion profile of the bare substrate was examined after the wear test, an elliptical area at the low angle and a circular crater at the high angle were observed (Fig. 1a). The erosive wear track at $90^{\circ}$ impact angles on the uncoated bare metal surface is in a circular form and in the form of a deep crater. The highest wear rate is observed at low impact angles $\left(30-45^{\circ}\right)$. The mechanism of wear in ductile metals occurs in the form of surface deformation and micro-cutting. The room temperature test results have a high rate of wear and the rate of wear increases after heat treatment. It has been observed that the surface hardness has decreased partially due to heat treatment.

When the wear tests performed on oxide based ceramic coatings, wear mechanism differs considerably from metallic surfaces. The erosive wear of ceramic coatings are influenced by both coating properties and impacting particle conditions including its size, velocity, impact angle $[5,6]$. The rate of erosive wear increases as a result of microcrack formation and crack growth on the coating. Erosive wear behavior of two layered ceramic coatings after solid particle wear test is generally the first phase of wear of the top layer, followed by the bond layer and increasing time to reach the substrate (Fig. 1b-d). The wear behavior is generally in the form of a brittle partial ductile type. The ceramic layer often exhibits brittle behavior, while the metal-based bond layer at the bottom exhibits a more ductile behavior. The wear rate varies depending on the structure of the coating layer and the surface resistance. Thickness, porosity and microcrack formations adversely affect the wear resistance of the coating. Increased thickness of the coating reduces the wear. Oxide based ceramic coatings have superior wear resistance when compared to bare metal surface.

The erosiv wear rate is higher in hard ceramic coatings at higher impact angles. When comparing among the ceramic coatings, it is clear that the wear resistance of the zirconate (Z) based coating is at the lowest level (Fig. 2). It was observed that surface resistance of the coatings increased after heat treatment. Sintering effect in the coating structure an increase the hardness and eleasticty of the coating. Heat treated coatings provide $10-20 \%$ higher wear resistance. In general, a lower mass loss was observed at lower impact angles.

Lower thickness (max. $80 \mu \mathrm{m})$ chromia coatings have shown the highest wear resistance (Fig. 3). Splat formation in the coating structure and the interaction of each splat are very important on mechanical properties of the coating. Coating thickness is an important parameter on wear rate. The wear rate is lower when the thickness is increased. The increase in splat layers provides resistance to the impact of solid particles.

In Fig. 4, microhardness changes of the coatings at room temperature and after heat treatment are compared with bare metal. The hardness of the coated surfaces is increased while the hardness of the metal surface de- creases after the heat treatment. Increased surface resistance of coatings play an active role in wear behavior. Possible minor level defects on the coating surface increase crack formation during the wear test. The splat layers and lamellar structure under the surface protect the coating for a certain period of time. The heat treatment helps the coating to resist hard particles in contact with the surface. Therefore, coated samples can provide wear protection by exhibiting superior wear performance compared to bare metal.

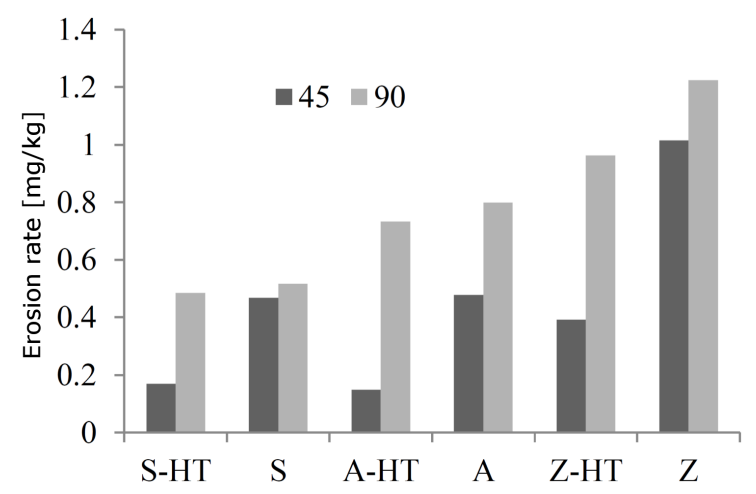

Fig. 2. Erosion rates comparison of the coatings at $45^{\circ}$ and $90^{\circ}$ impact angles before and after heat treatment (HT).

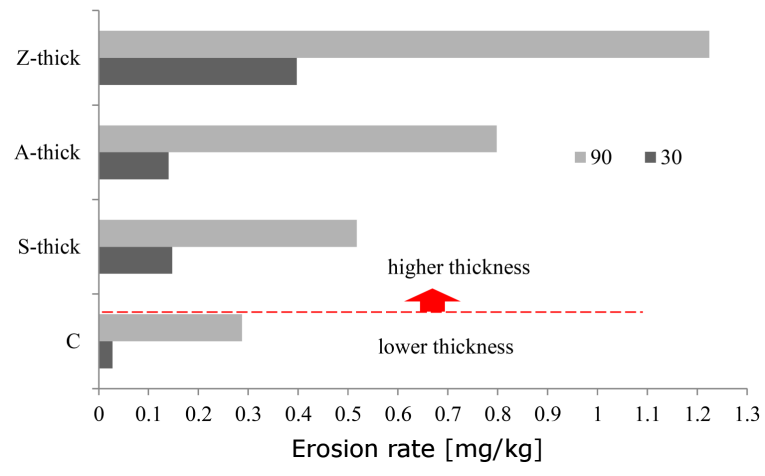

Fig. 3. Erosion rates comparison of the thicker coatings at $30^{\circ}$ and $90^{\circ}$ impact angles.

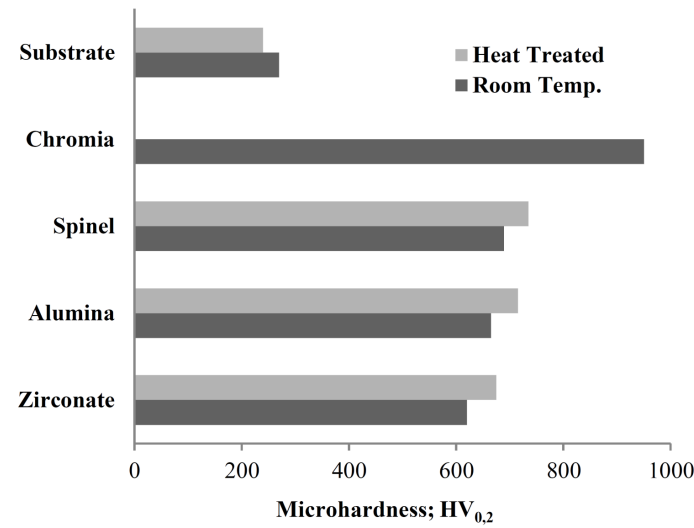

Fig. 4. Micro hardness comparison of the coatings after and before heat treatment. 

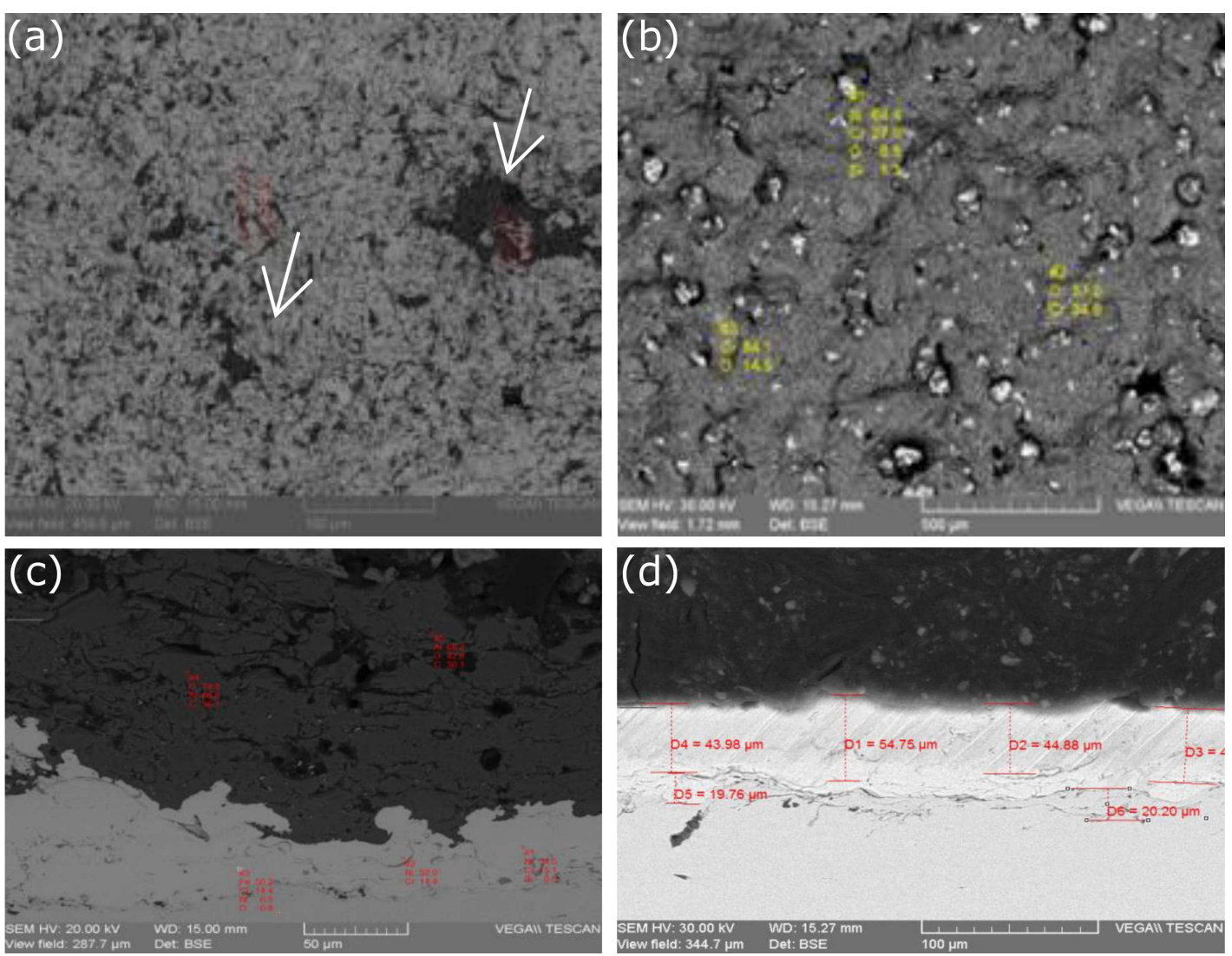

Fig. 5. Surface view (top) and cross section (bottom) microstructures of the (a), (c) alumina and (b), (d) chromia top coatings.

Figure 5 shows the top surface and cross-sectional views of the coatings. Micro cracks and micro porosities can be seen on the coating surfaces. Accelerated solid hard particles at high speed cause the number of cracks to increase and grow when strike the coating surface. Thus increasing the rate of wear at the surface as a result of the rate of crack growth. An intense microcrack formation can be clearly seen in electron microscopy studies on the top surface after 10 second at $90^{\circ}$ solid particle erosion test applied to alumina coating (Fig. 6). When 3D profilometry images of alumina based ceramic top coatings are examined, the highest surface roughness at room temperature is Ra: $8.64 \mu \mathrm{m}$ and Rz: $29.783 \mu \mathrm{m}\left(10 \mathrm{~s}, 90^{\circ}\right.$ impact angle). Surface roughness after the heat treatment was Ra: $6.745 \mu \mathrm{m}$ and Rz: $24.23 \mu \mathrm{m}$ and surface roughness decreased after heat treatment. The surface roughness values are reduced in the first stage together with the impact of solid particles at high speed. The second stage consists of micron scale cracks on the surface with increasing impact effect. These cracks move along the thickness of the coating having a lamellar structure and then increase the wear rate. The thickness and morphology of the splat, and hence the thickness of the coating, controls the wear rate and surface roughness. Comparatively the wear track profiles were measured with a 3D profilometer. The effect of heat treatment on surface roughness and wear track profile on the top surface of alumina coating are obvious in Fig. 7 The wear track size of the coating after heat treatment is smaller and surface roughness is lower. It is thought that the heat treatment reduces the micron scale defects on the surface and decreases the wear rate due to increasing the coating density and resistance.

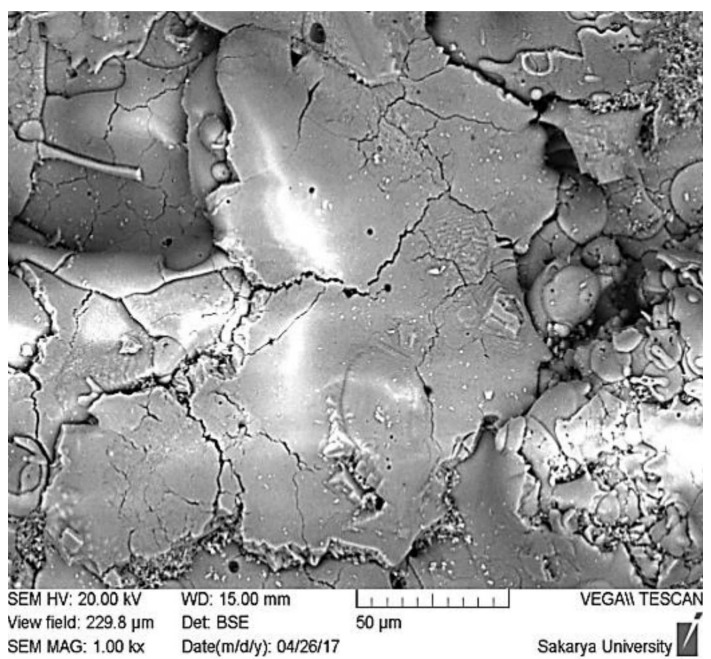

Fig. 6. Top surface of the alumina coating. Microcracks of the top coating after wear test at room temperature $\left(10 \mathrm{~s}, 90^{\circ}\right)$. 

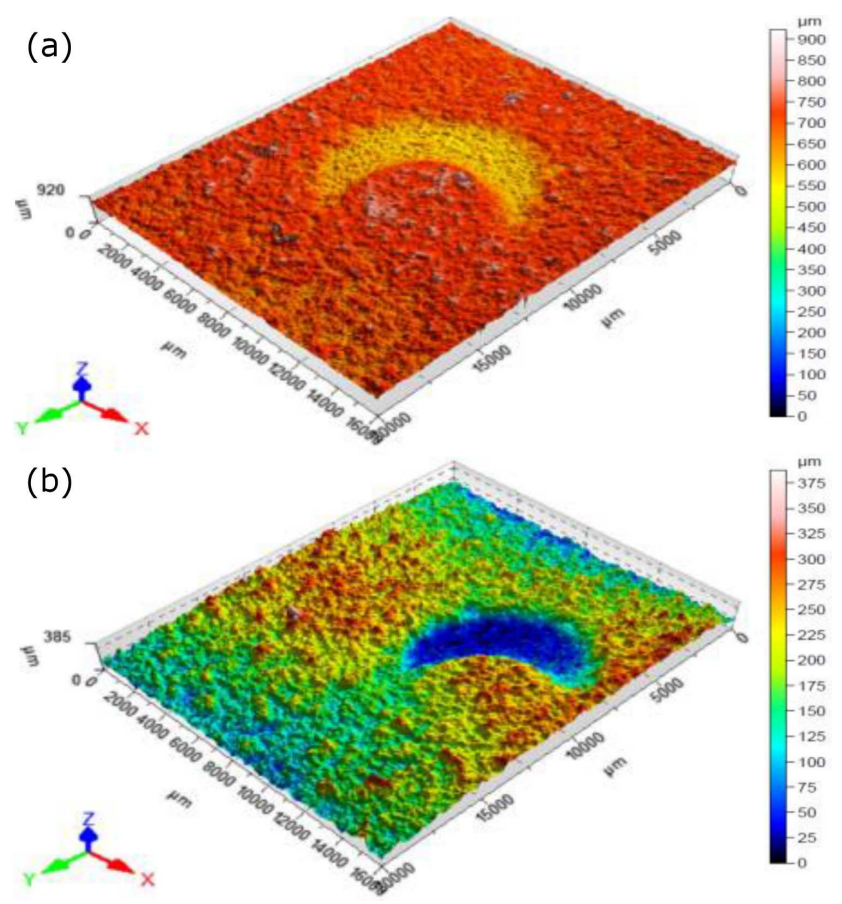

Fig. 7. Wear track profile of alumina coating (a) before and (b) after heat treatment.

\section{Conclusions}

The solid particle wear tests of the oxide based ceramic coatings produced in different thicknesses were evaluated both before and after the heat treatment. Erosive wear behaviour and mechanism of the flexicord flame spray coatings extensively investigated using scanning electron microscopy. Wear rates of variety oxide coatings have increased due to increased test duration in solid particle wear tests. The change in the impact angle of hard solid particles with the surface, wear rate changed. In this context, the hard ceramic coatings exhibited lower wear rate at low angles and higher wear loss at high angles.
This shows that the wear behavior in the coated case has changed significantly. The micro porosity and micron scale cracks in coating microstructure have direct effect on increasing the erosion rate of the coatings. As a result of heat treatment, the wear performance of all coatings has been increased. The increase in coating thickness provides an positive effect to reduce wear losses. The highest wear performance was observed in chromium oxide coatings. The deposition efficiency of chromium oxide coatings is limited to this spray gun. Although higher energy plasma spray systems are required, coating performance is satisfactory. The wear resistance of the stainless steel substrate can be increased 5-7 times by flame spray oxide coatings. Ceramic coatings can be easily used on metal surfaces with the flexicord flame spraying method.

\section{Acknowledgments}

The authors wish to thank F.Ustel (Sakarya University Thermal Spray Tech. R\&D Lab.), and S. Fidan, B. Onen (Kocaeli University, Civil Aviation Dept., Wear test Labrotary) for their support and interaction during the erosion test and characterization of this work. This study financially supported by Sakarya University Bapk Projects No:2013-09-08-003.

\section{References}

[1] G. Sundararajan, R. Manish, Trib. Int. 30, 339 (1997).

[2] J.R. Tavares Branco, R. Gansert, S. Sampath, C.C. Berndt, H. Herman, Mat. Res. 7, 147 (2004).

[3] K.V. Sreenivas Rao, K.G. Girisha, S. Eswar, Mat. Sci. Eng. 149, 1 (2016).

[4] E. Altuncu, S. Iriç, Acta Phys. Pol. A 132, 926 (2017).

[5] D. Aquaro, Mecc. 41, 539 (2006).

[6] ASTM G76-13, Standard Test Method for Conducting Erosion Tests by Solid Particle Impingement Using Gas Jets, ASTM International, West Conshohocken (PA) 2013. 